\title{
The effect of solvents and the thickness on structural, optical and electrical properties of ITO thin films prepared by a sol-gel spin-coating process
}

\author{
Mohsen Moradi-Haji Jafan • Mohammad-Reza Zamani-Meymian • \\ Rahmatollah Rahimi • Mahboubeh Rabbani
}

Received: 20 December 2013/Accepted: 12 February 2014/Published online: 28 February 2014

(C) The Author(s) 2014. This article is published with open access at Springerlink.com

\begin{abstract}
In this study, tin-doped indium oxide (ITO) thin films were produced by the sol-gel spin-coating technique with an inexpensive salt of indium $\left(\operatorname{In}\left(\mathrm{NO}_{3}\right)_{3-}\right.$ $\mathrm{H}_{2} \mathrm{O}$ ) and $\mathrm{SnCl}_{4}$ as indium and tin precursors (the molar ratio of $\mathrm{In:Sn}$ was 9:1), respectively. Then the prepared thin films were annealed in the temperature of $550{ }^{\circ} \mathrm{C}$ under argon atmosphere (the pressure of 10 torr). Polyvinylalcohol (PVA) was used as stabilizers in the synthesis of ITO sol. The prepared ITO thin films were characterized by EDX, XRD, FT-IR, UV-Vis spectroscopy and SEM images. The XRD patterns of the thin films indicated the main peak of the ( $\left(\begin{array}{ll}2 & 2\end{array}\right)$ plane corresponded to indium oxide with high degree of crystallinity. The FT-IR spectroscopy confirmed that indium tin oxide has been prepared by appearance of a peak at $470 \mathrm{~cm}^{-1}$ that can be assigned to the vibrations of In-O bonds. The optical direct band gap of ITO thin films was calculated about $3.98-4.17 \mathrm{eV}$ by optical transmittance measurements. The grain size of ITO nanoparticles was obtained at about $25-50 \mathrm{~nm}$ by SEM images. The electrical characterization was done by the four-point probe method to determine the sheet resistance and resistivity. The effects of coating number on ITO thin films properties were investigated. The low resistivity (sheet resistance of $2.5 \mathrm{k} \Omega / \mathrm{cm}^{2}$ ) and highly transparent films were obtained that can be applied as covers on heater windows. Appearance of a peak at $470 \mathrm{~cm}^{-1}$ can be
\end{abstract}

M. Moradi-Haji Jafan ( $₫)$ · M.-R. Zamani-Meymian Department of Physics (Solid State), Iran University of Science and Technology, Narmak, 16846-13114 Tehran, Iran e-mail: mohsenmoradi@physics.iust.ac.ir

R. Rahimi · M. Rabbani

Department of Chemistry, Iran University of Science and

Technology, Tehran, Iran assigned to the vibrations of In-O bonds and are characteristic of cubic $\mathrm{In}_{2} \mathrm{O}_{3}$.

Keywords TCO $\cdot$ Tin-doped indium oxide $\cdot$ ITO $\cdot$ PVA · Sol-gel $\cdot$ Resistance $\cdot$ Transmittance

\section{Introduction}

Thin films of transparent semiconductor have attracted interest because of its good transparent and conductive properties for the potential applications in electronic fields such as heater windows, dye synthesized solar cells and transparent electrodes [1-3]. Among the various transparent conductive oxides (TCOs) such as flour tin oxide (FTO), aluminum zinc oxide (AZO) and aluminum tin oxide (ATO), the best known is tin-doped indium oxide (ITO) due to its considerable characteristics of high optical transmittance over the visible spectrum, high conductivity, and chemical stability [4-6]. Often, $10 \mathrm{~mol} \%{\text { of } \mathrm{Sn}^{4+} \text { ions }}^{4}$ are dissolved into $\mathrm{In}_{2} \mathrm{O}_{3}$ lattice to form the ITO solution with maximum conductivity [7].

The deposition of TCOs on the substrate can be made using several physical or chemical methods, such as spincoating [8], magnetron sputtering [9], chemical vapor deposition (CVD) [10], vacuum evaporation [11], reaction evaporation [12] and the sol-gel process [6, 13-19]. The sol-gel method has several advantages, including simplicity, low cost, easily controlled doping levels and feasible preparation of large area films [6]. Furthermore, this method, as a chemical route procedure can be combined with deposition techniques such as spin- and dip-coating for use in the preparation of thin films [20-23]. This method is a very easy and economical technique to get high-quality ITO thin films. In addition, different salts of 
indium can be utilized to act as indium precursor for the synthesis of the ITO sol-gel solutions, indium nitrate is more appropriate for commercialized applications due to its low price rather than other indium salts [24]. On the other hand, the coating number is one of factors that has an effect on morphology and conductivity of thin films that has been studied previously [25], while the effect of type solvent on the ITO thin films has rarely been investigated $[23,26,27]$ and the influence of acetyl acetone and ethanol was not compared together yet.

In this paper, for the first time, the effect of both the solvents and the thickness was investigated on the structural, optical and electrical properties of the ITO films that were synthesized by the sol-gel spin-coating processes with $\mathrm{In}\left(\mathrm{NO}_{3}\right)_{3} \cdot \mathrm{H}_{2} \mathrm{O}$ and $\mathrm{SnCl}_{4}$ as indium and tin precursors, respectively. Polyvinylalcohol (PVA) was used as stabilizers in the synthesis of ITO sol. Ethanol and acetyl acetone were utilized as solvents to preparation of ITO sols. Acetyl acetone is a bidentate ligand that can be used for obtaining a homogeneous sol of ITO which may have resulted in uniform nanoparticles.

\section{Experimental procedure}

\section{Materials}

Indium tin oxide (ITO) thin films were prepared via sol-gel spin-coating (S-G-S) technique using indium nitrate hydrate $\left(\mathrm{In}\left(\mathrm{NO}_{3}\right)_{3} \cdot \mathrm{H}_{2} \mathrm{O}\right.$, Alfa Aesar $\left.99.99 \%\right)$ and tin chloride anhydrate $\left(\mathrm{SnCl}_{4}\right.$ Merck $\left.98 \%\right)$ as inorganic reactants, polyvinylalcohol (PVA, average molecular weight: 65,000, hydrolysis: 85.5-86.5, Dongyang Chem., Korea) as polymerizing agent and binding material, double-distilled water, absolute ethanol (Merck Co.) and acetyl acetone (AcAc, Merck Co., >98\%) as solvents and hydrochloric acid ( $\mathrm{HCl}$, Merck Co., $37 \%)$ as dispersing solvent.

\section{Preparation of sol}

For this purpose, first $1.1 \mathrm{~g}$ polyvinylalcohol (PVA) was dissolved in $30 \mathrm{ml}$ double-distilled water and the resultant solution was refluxed at $80{ }^{\circ} \mathrm{C}$ for $3 \mathrm{~h}$. Next $\operatorname{In}\left(\mathrm{NO}_{3}\right)_{3} \cdot \mathrm{H}_{2} \mathrm{O}$ was dissolved in double-distilled water, and the resultant solution (0.5 M, solution 1) was refluxed at $60^{\circ} \mathrm{C}$ for $30 \mathrm{~min}$. Then, the required amount of $\mathrm{SnCl}_{4}$ (with initial molar ratio of 9:1 for $\mathrm{In}: \mathrm{Sn}$ ) was dissolved in the two below-mentioned solvents at room temperature precursors:

(A) $0.025 \mathrm{~mol}(0.29 \mathrm{~mL})$ of $\mathrm{SnCl}_{4}$ was dissolved in $5 \mathrm{~mL}$ absolute ethanol and it was stirred for $30 \mathrm{~min}$.

(B) $0.025 \mathrm{~mol}(0.29 \mathrm{~mL})$ of $\mathrm{SnCl}_{4}$ was dissolved in $5 \mathrm{~mL}$ acetyl acetone and it was stirred for $30 \mathrm{~min}$.
Then the two obtained solutions $\mathrm{A}$ and B were separately added to solution 1 and refluxed at $60{ }^{\circ} \mathrm{C}$ for another $2 \mathrm{~h}$ ( $\mathrm{pH} 2.3$ ) under stirring. Several drops of hydrochloric acid were added to solution to prevent hydrolyzation of $\mathrm{SnCl}_{4}$ during a refluxing until a transparent ITO sol was achieved ( $\mathrm{pH}$ 1.6). The $\mathrm{Sn} / \mathrm{In}$ ratio was fixed at 10/90 wt\%, respectively. Finally, the obtained sol was aged for 2 days at room temperature.

\section{Deposition of ITO thin films}

Glass substrates were washed with a detergent and cleaned ultrasonically with isopropanol, acetone, ethanol and deionized water for $6 \mathrm{~min}$, respectively. Then, the prepared sol was deposited on that substrate using spin-coating technique. Spin parameters, including spin speed and time were fixed at 2,500 rpm and $20 \mathrm{~s}$, respectively. The coated substrates were heated at $150{ }^{\circ} \mathrm{C}$ for $20 \mathrm{~min}$ after each step in order to dry the indium tin hydroxide layers. Spinning and drying cycles were repeated in order to reach the desired film thickness.

To prepare ITO thin films (with In:Sn atomic ratios of 90:10) using the above-mentioned process, in addition to water, two other types of solvent have been utilized: (A) ethanol and (B) AcAc. The glass substrates on which the samples were prepared using ethanol and water are designated as S-A-1, S-A-2, S-A-3 and S-A-4 that were coated $3,5,7$, and 9 times, respectively, and the glass substrates on which the samples prepared using the acetyl acetone and water are designated as S-B-1 and S-B-2 that were coated 3 and 5 times, respectively. All of the samples were heated in an oven at a rate of $10{ }^{\circ} \mathrm{C} / \mathrm{min}$ up to $500{ }^{\circ} \mathrm{C}$, held for $30 \mathrm{~min}$ in air, cooled down to room temperature then annealed at $550{ }^{\circ} \mathrm{C}$ for $1 \mathrm{~h}$ under argon atmosphere .

Scheme 1 shows the overall flow chart for ITO thin films preparation via sol-gel spin-coating technique.

\section{Characterization of thin film}

The crystalline phases of the ITO thin films were analyzed using X-ray diffraction (XRD, JEOL diffractometer) with monochromatized $\mathrm{Cu} \mathrm{K} \alpha$ radiation $(\lambda=1.54056 \AA)$ in the range of $15^{\circ}-65^{\circ}$ with step size of $0.1^{\circ}$. The optical characteristics of the ITO thin films were tested through a UVVis spectrophotometer (Rayleigh UV-2100) in the UV and visible ranges (wavelengths of 320-900 nm) for determining the optical band gap values. The morphology of the ITO thin films were observed by scanning electronic microscope (SEM, Tescan Vega II) and the elemental composition of tin-doped titanium dioxide thin film was determined by energy dispersive X-ray (EDX) analysis coupled with SEM. Fourier transform infrared (FT-IR) 
Scheme 1 The ITO thin films preparation via sol-gel spincoating technique

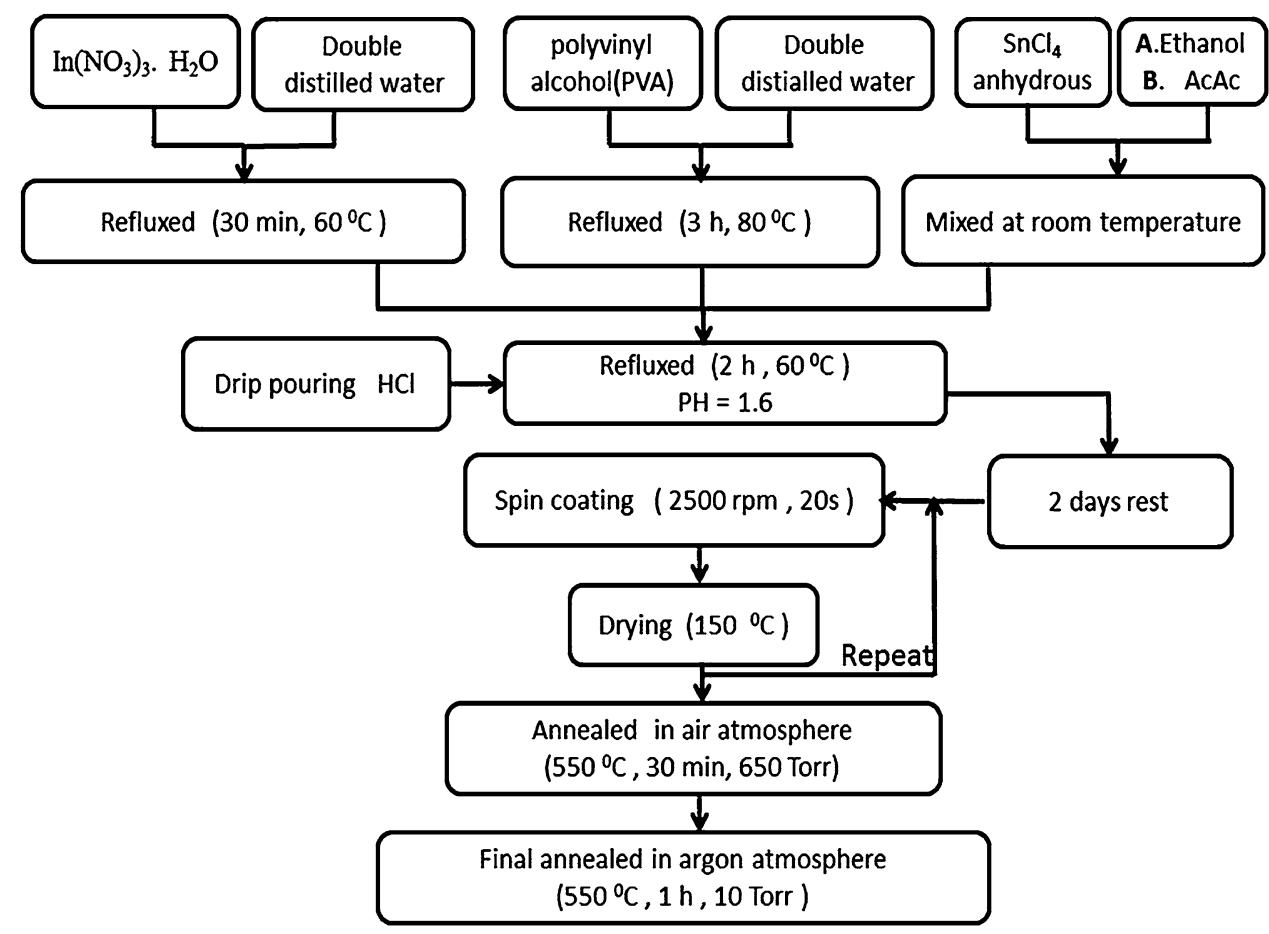

spectra were recorded on a Shimadzu-8400S spectrometer in the range of $400-4,000 \mathrm{~cm}^{-1}$ using $\mathrm{KBr}$ pellets. The values of sheet resistance of the thin films were recorded by a Jandel resistivity meter (RM3-AR) with a four-point probe head at room temperature, repeating the measurements in 12 different points of the thin films.

\section{Results and discussion}

\section{Microstructural studies}

The morphologies of the ITO thin films were observed by SEM images (Fig. 1). As shown in these images, the ITO thin films that were prepared with 3 or 5 times coating, are nanoclusters with approximately $20-40 \mathrm{~nm}$ in size. The good regularity of these samples is due to the presence of PVA. Polyninylalcohol is an organic polymer that during annealing at $550{ }^{\circ} \mathrm{C}$ is removed, and the ITO nanoparticles with regular structure remained. Also, this organic material can prepare mesostructures of ITO thin films. It is interesting to note that two specific functions of the organic binder, PVA are in operation in the synthesis. These are: (1) to increase wettability of the precursor due to the increase of hydroxyl groups and (2) to generate nanoclusters through its decomposition. During thermal curing of the sol-gel layer, decomposition of PVA starts at about $250{ }^{\circ} \mathrm{C}$ when the $\mathrm{C}-\mathrm{O}$ bonds are possibly broken (Scheme 2) and the nanoclusters of the metal oxides are formed [15].
By increasing coating number from 3 to 5 times, the numbers of grains have increased and the empty places have been filled, while the size of grains has grown very low. When the number of coating is raised to more than 5 (S-A-3 and S-A-4), the nanoclusters are attached together and their grain sizes become larger. This occurrence led to cracking on the surfaces of ITO thin films caused an increasing of the sheet resistance of the ITO thin films (S-A-4). The repeating of coating number led to agglomeration of materials and increasing of crack due to the presence of PVA. The samples of that prepared in the presence of ethanol have larger grains in comparison to samples prepared in the presence of AcAc.

During thermal curing of the sol-gel layer, decomposition of PVA starts at $250{ }^{\circ} \mathrm{C}$ when the bond $\mathrm{C}-\mathrm{O}$ is possibly broken and the nanoclusters of the metal oxides are formed in the PVA decomposed area.

The cross-section SEM pictures of ITO films (S-A-2 and S-A-3 samples) are given in Fig. 2. As can be seen from these images, the thickness of ITO films for S-A-2 and S-A-3 was estimated to be about 120 and $165 \mathrm{~nm}$, respectively.

\section{Electrical properties}

The sheet resistivity of S-A-1, S-A-2, S-A-3 and S-A-4 samples is shown in Fig. 3a. Here tin acts as a dopant in the $\mathrm{In}_{2} \mathrm{O}_{3}$ lattice and substitute on the indium sites to bind with the interstitial oxygen. When the coating number increases, the sheet resistance decreases because of increasing ITO 
Fig. 1 The SEM images of the ITO thin films prepared with different conditions: a S-A-1, b S-A-2, c S-A-3, d S-A-4, e SB-1 and $\mathbf{f}$ S-B-2
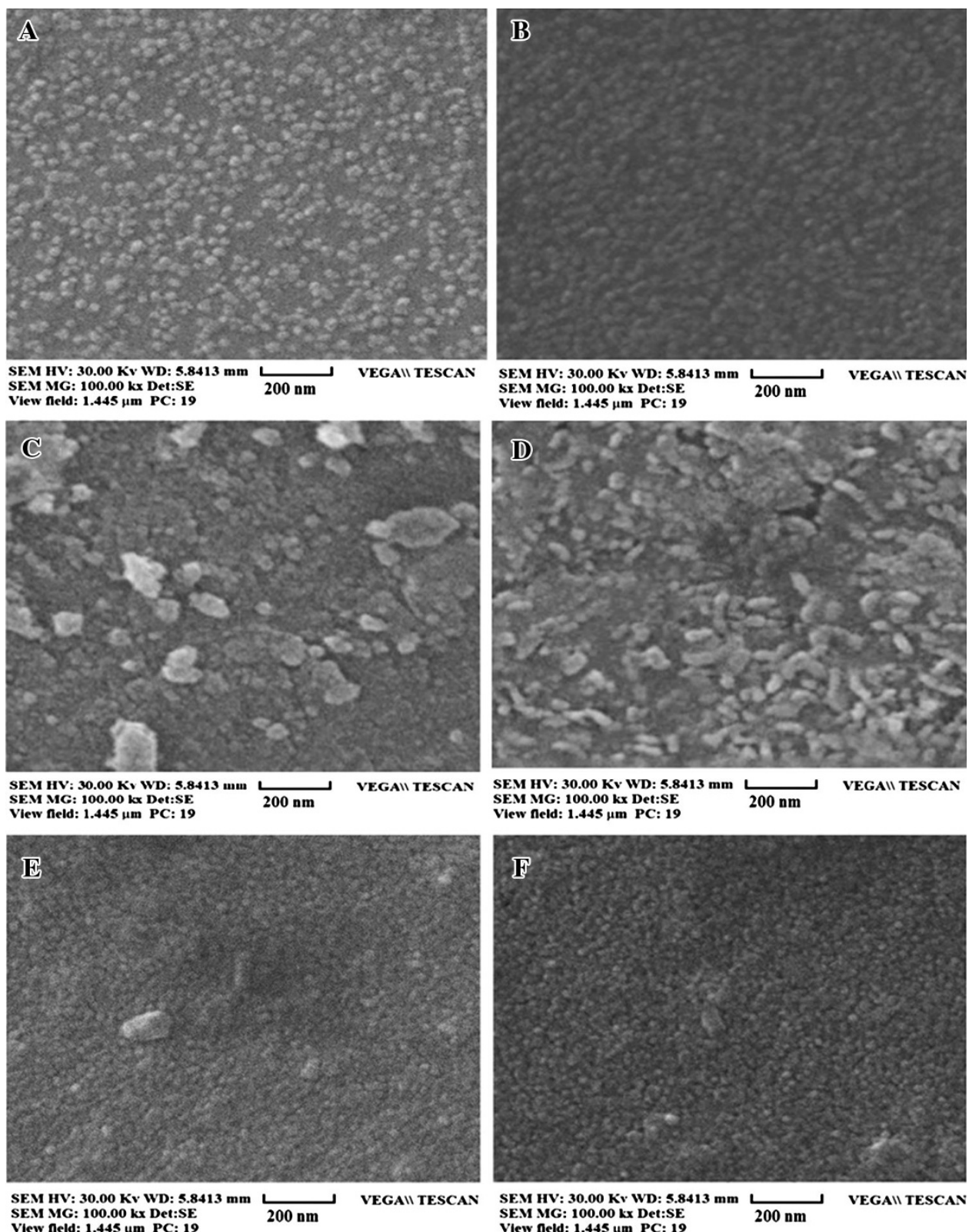
SEM MG: $100.00 \mathrm{kX}$ Det:SE
View neld: $1.445 \mu \mathrm{m}$ PC: 19

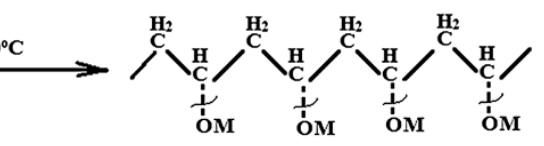<smiles>CCCCC(O)CC(O)CC(O)CC(C)O</smiles>

$>250^{\circ} \mathrm{C}$<smiles>CC[C](O)CC(O)CC(O)C[C](C)O</smiles>

Scheme 2 Mechanism of ITO formation by using PVA

nanoparticles. It is interesting to note that coating more than seven times led to increase of sheet resistance, while at previous lectures, sheet resistance decreased with increasing of coating layers. It can occur due to lower interaction of layer with surface and the increasing of micro-cracks and defects in the structure.
The bulk electrical resistivity $\rho$ can be calculated using: $\rho=\mathrm{R}_{\mathrm{S}} \mathrm{d}$,

where $\rho=$ sample resistivity (in $\Omega \mathrm{cm}$ ), $d=$ conducting layer thickness (in $\mathrm{cm}$ ), and $R_{\mathrm{S}}=$ sheet resistance (in $\Omega / \mathrm{cm}^{2}$ ) 
Fig. 2 The cross-section SEM pictures of ITO thin film. a Sample S-A-2 and b sample S-A-3
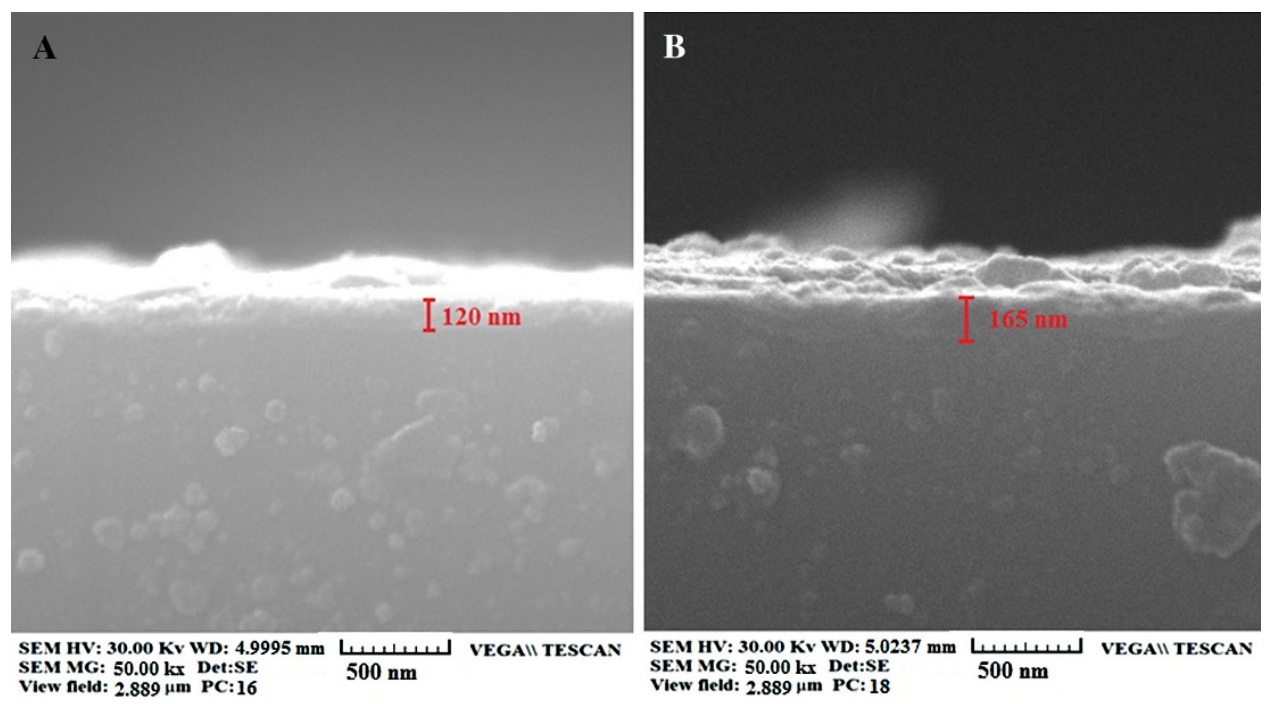

Fig. 3 The sheet resistance of ITO thin films prepared in the presence of a ethanol with 3, 5, 7 and 9 coating number and b ethanol and AcAc with 3 and 5 coating number
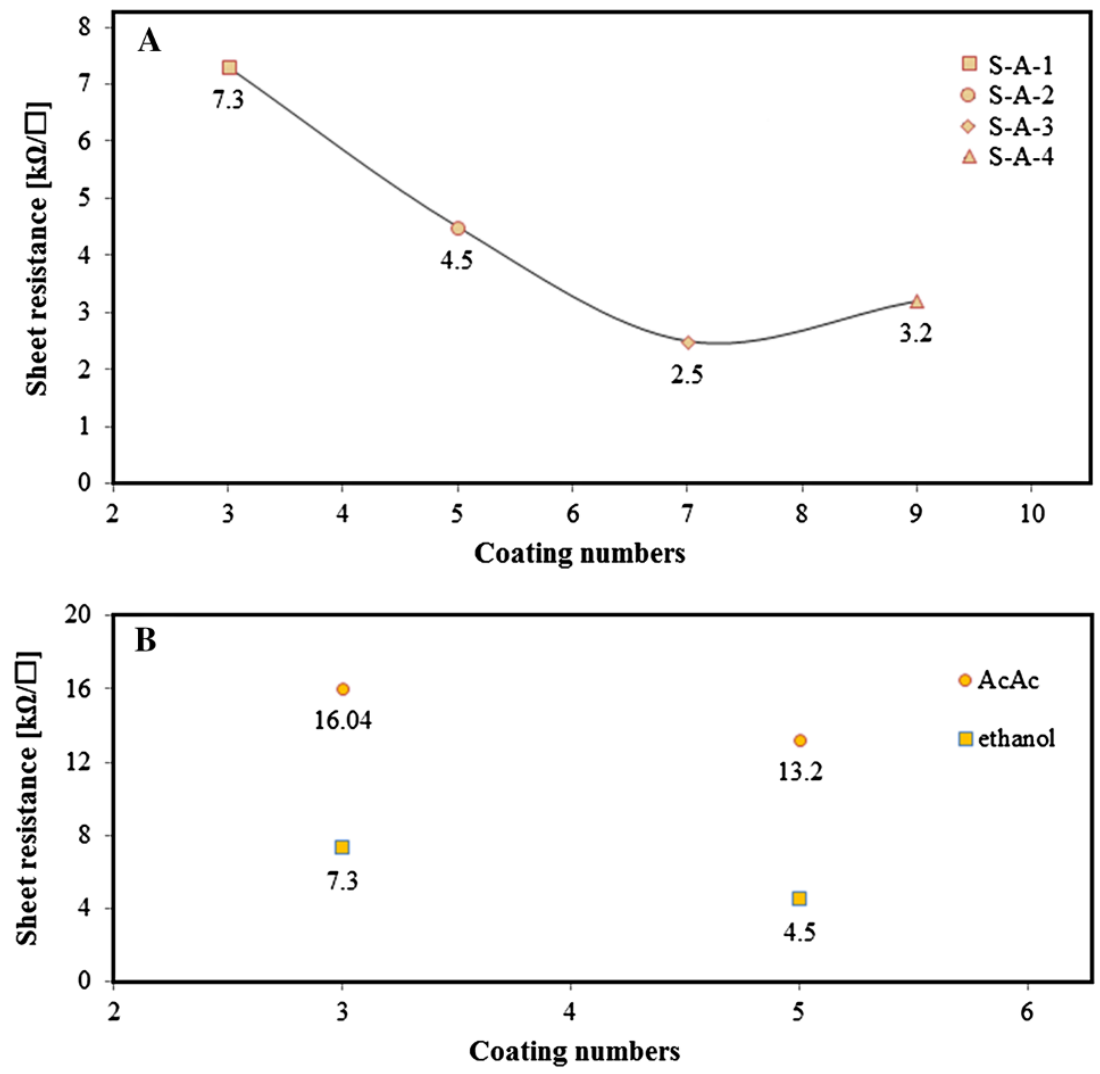

The sheet resistance, resistivity and thickness of samples are listed in Table 1. As shown in this table, the S-A-1 with seven times coating has the best conductivity of 24.24 $(\Omega \mathrm{cm})^{-1}$ (sheet resistivity $=2.5 \mathrm{k} \Omega / \mathrm{cm}^{2}$ ). The best value of the sheet resistance obtained via a sol-gel method (around $\left(2.3-2.7 \mathrm{k} \Omega / \mathrm{cm}^{2}\right)$ is much higher than that of thin films deposited by high vacuum techniques such as sputtering and ion beam technique. This relatively high sheet resistance is associated with the porous structure and the small grain size of the gel ITO thin film, independent of the level of doping.

In Fig. 3b, the sheet resistivity of four samples has been compared together (S-A-1, S-A-2, S-B-1 and S-B-2). The samples prepared in the presence of ethanol (S-A-1 and S-A-2) have better conductivity than the samples prepared in the presence of AcAc (S-B-1 and S-B-2). Therefore, application of water and ethanol is better than water and AcAc for synthesis of ITO. AcAc is a chelating agent that 
Table 1 The sheet resistance, resistivity and thickness of samples

\begin{tabular}{lllll}
\hline Sample & $\begin{array}{l}\text { Coating } \\
\text { number }\end{array}$ & $\begin{array}{l}\text { Sheet } \\
\text { resistance } \\
\left(\mathrm{k} \Omega / \mathrm{cm}^{2}\right)\end{array}$ & $\begin{array}{l}\text { Resistivity } \\
(\Omega \mathrm{cm}) \times 10^{-4}\end{array}$ & $\begin{array}{l}\text { Thickness } \\
(\mathrm{nm})\end{array}$ \\
\hline S-A-1 & 3 & $\sim 7.2-7.5$ & $\sim 511$ & $\sim 70$ \\
S-A-2 & 5 & $\sim 4.4-4.6$ & $\sim 876$ & $\sim 120$ \\
S-A-3 & $\mathbf{7}$ & $\sim \mathbf{2 . 3 - 2 . 7}$ & $\sim \mathbf{4 1 2 . 5}$ & $\sim \mathbf{1 6 5}$ \\
S-A-4 & 9 & $\sim 2.9-3.6$ & $\sim 704$ & $\sim 220$ \\
S-B-1 & 3 & $\sim 15.7-16.3$ & $\sim 792$ & $\sim 60$ \\
S-B-2 & 5 & $\sim 12.5-13.9$ & $\sim 1,600$ & $\sim 100$ \\
\hline
\end{tabular}

The sample with maximum conductivity are in bold

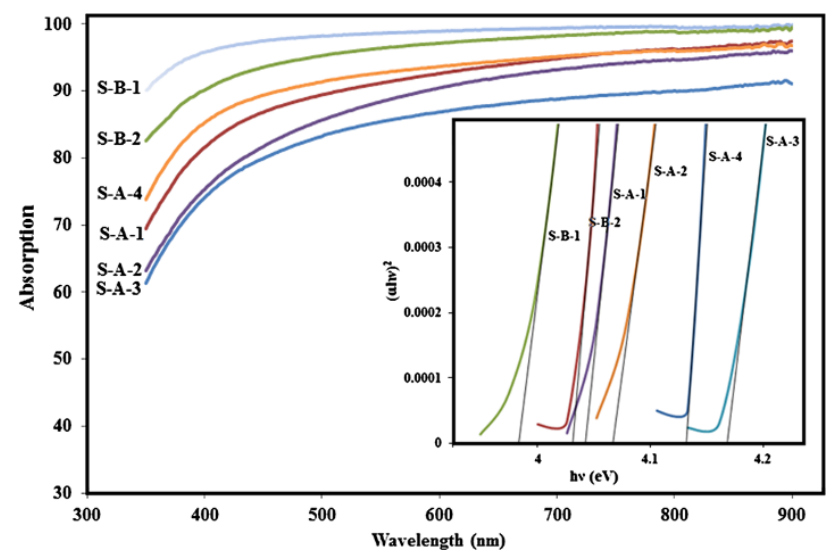

Fig. 4 UV-Vis transmittance spectra of thin films. Inset the plot of $(\alpha h v)^{2}$ versus $h v$ to determine the band gap of ITO thin films at various conditions

reacts with tin and indium ions extremely and form complex, therefore the resulting solvent is yellow. The ethanol can react with tin and indium by hydrogen bonding and therefore these metal ions can disperse in water uniformly.

\section{Optical properties}

Figure 4 shows UV-Vis transmittance spectra of thin films (the baseline is the glass). All samples are highly transparent in the visible region (more than $85 \%$ ), that is due to the presence of $\mathrm{Sn}$ at structure of $\mathrm{In}_{2} \mathrm{O}_{3}$, because the transition can be modified by addition of atoms with ionic radii smaller than that of indium and with a cation/ oxygen ionic radii ratio equal to $0.86\left[r^{4+}(\mathrm{Sn})=0.69 \AA\right.$, $\left.r^{3+}(\mathrm{In})=0.80 \AA, r^{4+}(\mathrm{Sn}) / r^{3+}(\mathrm{In})=0.86\right]$. According to this figure, the transmittance of the ITO thin films increased with decrease of the coating number until 3 times, reached the maximum transmittance of more than $90 \%$ and then decreased to lower degrees with addition of the coating number. The samples prepared in the presence of AcAc (S-B-1 and S-B-2), are more transparent than S-A-1, S-A-2, S-A-3 and S-A-4. Absorption

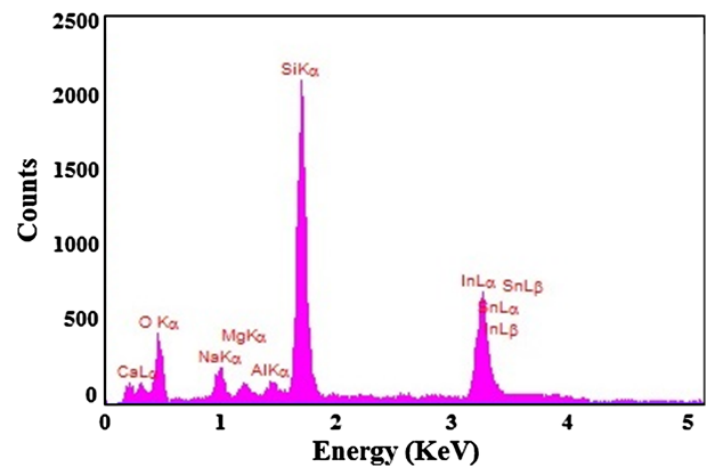

Fig. 5 The EDX results of prepared ITO thin film

spectra of ITO thin films (not shown here) give a broad band at around $310 \mathrm{~nm}(4.0 \mathrm{eV})$ which is due to the excitonic transition of the ITO nanostructures from the valence band to the conduction band [16]. According to Fig. 4a, the optical transmittance of the thin films decreased with increase of the coating number. Sample S-B-1 has the best transmittance than other samples. The optical direct band gap values of the ITO thin films are shown in the inset of Fig. 4. The absorption coefficient for the direct allowed transition can be written by using Tauc's relation:

$\alpha h \vartheta=\alpha_{0}\left(h \vartheta-E_{g}\right)^{1 / 2}$,

where $h v, \alpha_{0}$ and $E_{g}$ are photon energy, constant and optical band gap of the ITO thin films, respectively. The absorption coefficient $(\alpha)$ of the ITO at different wavelengths can be calculated from the transmission spectra. The thickness of the films was estimated from the cross-section SEM images.

We evaluated effective band gap of the ITO thin films from the plot, $(\alpha h v)^{2}$ vs. $h v$ (Fig. 4). It is known that in the degenerated semiconductors such as ITO, the optical band gap can be affected by changing the thickness of thin films. As illustrated in Fig. 4, the optical direct band gap values of ITO thin films have changed from 3.98 to $4.17 \mathrm{eV}$ by changing coating number and type of solvents (ethanol and AcAc). The highest band gap is related to S-A-3. This sample has shown lowest sheet resistance. The optical band gap shift to higher energy with increase in coating numbers is due to the improvement of the crystallinity, and thereby increasing the carrier concentration (Burstein-Moss effect) [28].

The element analysis by EDAX analysis

According to the results obtained from energy dispersive $\mathrm{X}$-ray analysis (EDX), it is recognized that $10.6 \%$ of tin percentage entered to the $\operatorname{In}_{2} \mathrm{O}_{3}$ lattice that is proportional to the amount of $10 \% \mathrm{Sn}$ used for synthesis of ITO (Fig. 5). 


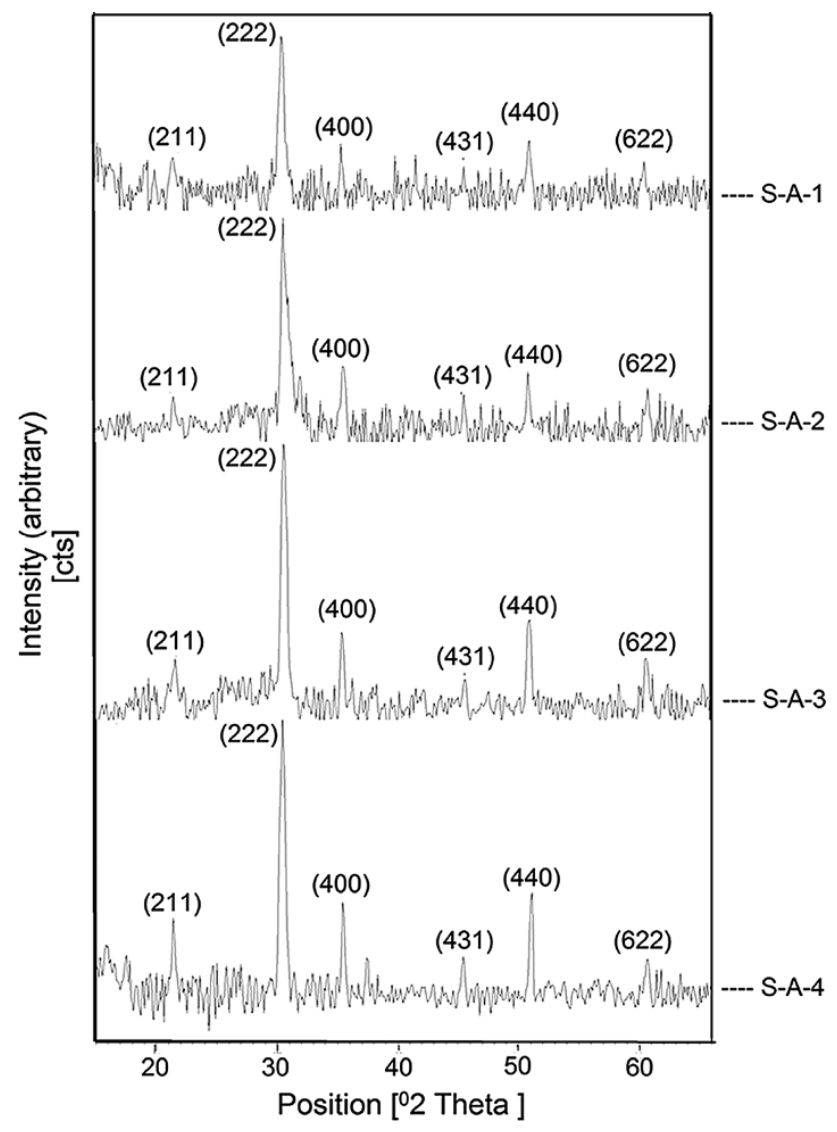

Fig. 6 The XRD spectra of ITO thin films prepared in the presence of ethanol with 3, 5, 7 and 9 times coating number

\section{X-ray diffraction studies (XRD)}

Figure 8 shows the XRD pattern of ITO thin films prepared from indium nitrate in the presence of ethanol with $3,5,7$ and 9 times coating number. This figure shows that the gel films treated up to $550{ }^{\circ} \mathrm{C}$ have sharp diffraction peaks that suggested good crystallization. All the peaks can be indexed to a cubic $\operatorname{In}_{2} \mathrm{O}_{3}$ (JCPDS 06-0416) with a Space group La3. The absence of tin oxide peaks in XRD pattern shows that tin atoms doped into $\operatorname{In}_{2} \mathrm{O}_{3}$ structure because the EDX analysis recognized the presence of $\mathrm{Sn}$ atoms in the structure of ITO film, but the only phase that can be observed in XRD pattern is ITO phase. Their lattice constants are smaller than the standard $\operatorname{In}_{2} \mathrm{O}_{3}$ with lattice constant $a=10.11 \AA$, because the $\mathrm{Sn}^{4+}$ ionic radius $(0.69 \mathrm{~nm})$ is smaller than $\mathrm{In}^{3+}$ ionic radius $(0.80 \mathrm{~nm})$, which will lead to the decrease of the planar spacing of $\operatorname{In}_{2} \mathrm{O}_{3}$ crystal lattice [1]. As shown in Fig. 8, the peaks are affected by coating number. It is interesting to note that by increasing the coating number, the peaks of samples are sharper and thinner, because the crystallites are larger. The sample of S-A-3 with seven times coating has the highest intensity $\left(I_{0}=189.4\right)$ and the
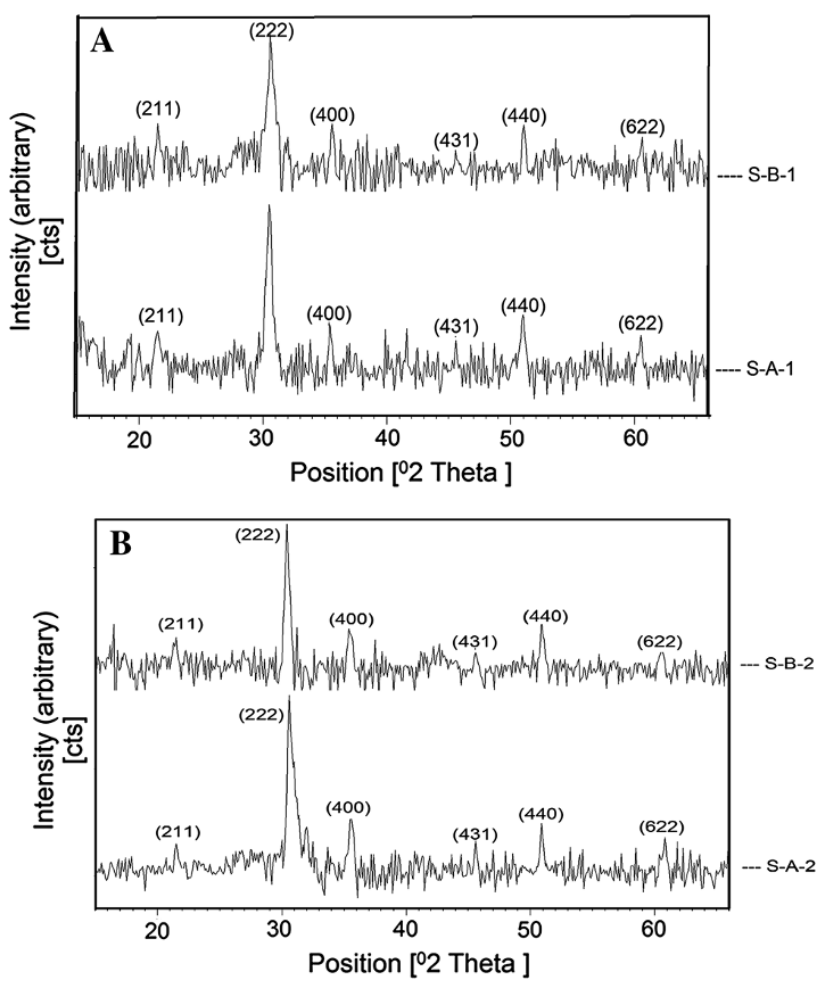

Fig. 7 The XRD patterns of samples a S-A-1 compared to S-B-1 and b S-A-2 compared to S-B-2

closest d-space value to its reference than the other samples. The repeating of coating number more than seven times maybe lead to agglomeration of materials and increasing of crack due to presence of PVA and decreasing of crystallinity.

In Figs. 6, 7, the XRD patterns of samples prepared in the presence of ethanol (S-A-1 and S-A-2) are compared to samples prepared in the presence of AcAc (S-B-1 and $\mathrm{S}-\mathrm{B}-2)$. As shown in this figure both are cubic structures of $\mathrm{In}_{2} \mathrm{O}_{3}$, but the peaks belonging to ethanol (S-A-1 and $\mathrm{S}-\mathrm{A}-2$ ) are sharper and thinner than S-B-1 and S-B-2, respectively. These show that their crystallites are bigger and therefore their morphology and conductivity are better than the samples prepared in the presence of AcAc. The $I / I_{0}$ and $\left(d-d_{\mathrm{s}}\right) / d_{\mathrm{s}}$ values and crystallite size (obtained from Scherrer equation) of orientations of all samples are listed in Table 2.

\section{FT-IR spectroscopy}

The typical IR spectra of ITO obtained by drying indium tin hydroxide colloidal solution followed by annealing at $550{ }^{\circ} \mathrm{C}$ are shown in Fig. 8. Appearance of a peak at $470 \mathrm{~cm}^{-1}$ can be assigned to the vibrations of In-O bonds and are characteristic of cubic $\operatorname{In}_{2} \mathrm{O}_{3}$ [29]. The peak at $1,050 \mathrm{~cm}^{-1}$ is assigned to the stretching vibration of $\mathrm{Si}-\mathrm{O}-$ $\mathrm{Si}$ bond (in glass). 
Table 2 The $I / I_{0}$ and $\left(d-d_{\mathrm{s}}\right) / d_{\mathrm{s}}$ values and crystallite size of orientations of all samples

\begin{tabular}{|c|c|c|c|c|c|c|c|}
\hline \multirow[t]{2}{*}{ Orientation } & \multicolumn{7}{|l|}{ Sample } \\
\hline & $\begin{array}{l}\text { S-A-1 } \\
\text { Coat numbers } 3\end{array}$ & $\begin{array}{l}\text { S-A-2 } \\
\text { Coat numbers } 5\end{array}$ & $\begin{array}{l}\text { S-A-3 } \\
\text { Coat numbers } 7\end{array}$ & $\begin{array}{l}\text { S-A-4 } \\
\text { Coat numbers } 9\end{array}$ & $\begin{array}{l}\text { S-B-1 } \\
\text { Coat numbers } 3\end{array}$ & $\begin{array}{l}\text { S-B-2 } \\
\text { Coat numbers } 5\end{array}$ & $\begin{array}{l}\text { JCPDS } \\
006-0416\end{array}$ \\
\hline \multicolumn{8}{|l|}{ (211) } \\
\hline$I / I_{0}$ & 17.6 & 17.9 & 18.2 & 18.1 & 20.8 & 21.4 & 14 \\
\hline$\frac{d-d_{\mathrm{s}}}{d_{\mathrm{s}}}$ & 0.48 & 0.1 & 0.1 & 0.3 & 0.7 & 0.1 & \\
\hline $\begin{array}{l}\text { Crystallite size }(\AA) \\
(222)\end{array}$ & 206 & 269 & 279 & 207 & 279 & 165 & \\
\hline$I / I_{0}$ & $100\left(I_{0}=122.06\right)$ & $100\left(I_{0}=152.4\right)$ & $100\left(I_{0}=189.4\right)$ & $100\left(I_{0}=187.5\right)$ & $100\left(I_{0}=100.9\right)$ & $100\left(I_{0}=124.2\right)$ & 100 \\
\hline$\frac{d-d_{\mathrm{s}}}{d_{\mathrm{s}}}$ & 0.52 & 0.1 & 0.1 & 0.4 & 0.2 & 0.1 & \\
\hline $\begin{array}{l}\text { Crystallite size }(\AA) \\
(400)\end{array}$ & 140 & 209 & 168 & 137 & 211 & 168 & \\
\hline$I / I_{0}$ & 30.2 & 31.7 & 30.37 & 31.52 & 31.9 & 32.2 & 30 \\
\hline$\frac{d-d_{\mathrm{s}}}{d_{\mathrm{s}}}$ & 0.35 & 0.2 & 0.1 & 0.1 & 0.07 & 0.1 & \\
\hline $\begin{array}{l}\text { Crystallite size }(\AA) \\
(431)\end{array}$ & 212 & 169 & 288 & 288 & 212 & 288 & \\
\hline$I / I_{0}$ & 10.44 & 11.97 & 11.25 & 10.34 & 13.84 & 11.93 & 10 \\
\hline$\frac{d-d_{\mathrm{s}}}{d_{\mathrm{s}}}$ & 0.1 & 0.4 & 0.1 & 0.3 & 0.1 & 0.4 & \\
\hline $\begin{array}{l}\text { Crystallite size }(\AA) \\
(440)\end{array}$ & 292 & 146 & 292 & 221 & 297 & 221 & \\
\hline$I / I_{0}$ & 32.6 & 33.3 & 34.2 & 34 & 36 & 36 & 35 \\
\hline$\frac{d-d_{\mathrm{s}}}{d_{\mathrm{s}}}$ & 0.1 & 0.5 & 0.2 & 0.1 & 0.1 & 0.1 & \\
\hline $\begin{array}{l}\text { Crystallite size }(\AA) \\
(622)\end{array}$ & 149 & 224 & 180 & 226 & 224 & 224 & \\
\hline$I / I_{0}$ & 17.62 & 19.54 & 20.04 & 18.9 & 23.7 & 24 & 25 \\
\hline$\frac{d-d_{\mathrm{s}}}{d_{\mathrm{s}}}$ & 0.1 & 0.1 & 00 & 0.1 & 0.3 & 0.3 & \\
\hline Crystallite size $(\AA)$ & 317 & 156 & 469 & 234 & 187 & 187 & \\
\hline
\end{tabular}

The sample with maximum conductivity are in bold

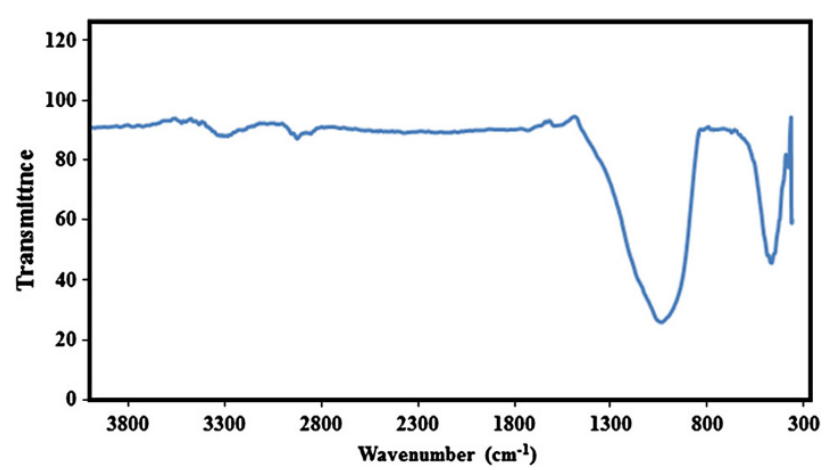

Fig. 8 Infrared absorption spectra of tin-doped indium oxide prepared by ethanol

\section{Conclusions}

In summary, we have reported a simple method for the preparation of SGS (sol-gel spin coating) ITO thin films on a glass substrates at $550{ }^{\circ} \mathrm{C}$ by aqueous precursors. We used polyvinylalcohol (PVA) for synthesis of Sn-doped
$\mathrm{In}_{2} \mathrm{O}_{3}$ as binding agent and to increase wettability of the precursor due to the increase of hydroxyl groups that led to the generation of nanoclusters through its decomposition. Nanostructures of the thin films were characterized by scanning electron microscopy (SEM) and their transparency was investigated by UV-visible spectroscopy. The results demonstrate that usage of PVA lead to a homogenized surface and increase of transparency of $\mathrm{In}_{2} \mathrm{O}_{3}$. The highest band gap is related to $\mathrm{S}-\mathrm{A}-3(4.17 \mathrm{eV})$ that has been made by seven times coating with gel prepared in the presence of ethanol. Therefore, the presence of ethanol is better than acetyl acetone as solvent in the synthesis of ITO via this method. AcAc is an appropriate agent to prepare transparent thin films; its presence led to formation of transparent thin film but fabrication of smaller particles in presence of AcAc decreases the conductivity of thin films.

This sample has shown the lowest sheet resistance $\left(2.5 \mathrm{k} \Omega / \mathrm{cm}^{2}\right)$, its XRD spectra presented sharper and thinner peaks than others and the thickness of ITO films for this sample is estimated to be about $120 \mathrm{~nm}$. The results 
showed that higher coating number causes higher resistance. The repeating of coating number more than seven times may have led to agglomeration of materials and increasing of crack due to the presence of PVA and decreasing of crystallinity.

Open Access This article is distributed under the terms of the Creative Commons Attribution License which permits any use, distribution, and reproduction in any medium, provided the original author(s) and the source are credited.

\section{References}

1. Zhang, H., Ye, F., Liu, L., Xu, H., Sun, C.: Synthesis of indium tin oxide nanotubes using 2-methoxyethanol as solvent via simple template method. J. Alloy. Compd. 504, 171-176 (2010)

2. Moholkar, A.V., Pawar, S.M., Rajpure, K.Y., Ganesan, V., Bhosale, C.H.: Effect of precursor concentration on the properties of ITO thin films. J. Alloy. Compd. 464, 387-392 (2008)

3. Kerkache, L., Layadi, A., Mosser, A.: Effect of oxygen partial pressure on the structural and optical properties of dc sputtered ITO thin films. J. Alloy. Compd. 485, 46-50 (2009)

4. Mohammadi, S., Abdizadeh, H., Golobostanfard, M.R.: Optoelectronic properties of molybdenum doped indium tin oxide nanostructured thin films prepared via sol-gel spin coating. Ceram. Int. 39, 6953-6961 (2013)

5. Beaurain, A., Luxembourg, D., Dufour, C., Koncar, V., Capoen, B., Bouazaoui, M.: Effects of annealing temperature and heattreatment duration on electrical properties of sol-gel derived indium-tin-oxide thin films. Thin Solid Films 516, 4102-4106 (2008)

6. Cho, H., Yun, Y.-H.: Characterization of indium tin oxide (ITO) thin films prepared by a sol-gel spin coating process. Ceram. Int. 37, 615-619 (2011)

7. Alam, M.J., Cameron, D.C.: Optical and electrical properties of transparent conductive ITO thin films deposited by sol-gel process. Thin Solid Films 377, 455-459 (2000)

8. Jin, C., You, I.-K., Kim, H.-K.: Effect of rapid thermal annealing on the properties of spin-coated $\mathrm{In}-\mathrm{Zn}-\mathrm{Sn}-\mathrm{O}$ films. Curr. Appl. Phys. 13(Suppl 2), S177-S181 (2013)

9. Kwok, H.S., Sun, X.W., Kim, D.H.: Pulsed laser deposited crystalline ultrathin indium tin oxide films and their conduction mechanisms. Thin Solid Films 335, 299-302 (1998)

10. Ryabova, L.A., Salun, V.S., Serbinov, I.A.: Transparent conductive films of $\mathrm{In}_{2} \mathrm{O}_{3}$ :Sn prepared by the pyrolysis method. Thin Solid Films 92, 327-332 (1982)

11. Korobov, V., Leibovitch, M., Shapira, Y.: Structure and conductance evolution of very thin indium oxide films. Appl. Phys. Lett. 65, 2290-2292 (1994)

12. Ma, J., Li, S.-Y., Zhao, J.-Q., Ma, H.-L.: Preparation and properties of indium tin oxide films deposited on polyester substrates by reactive evaporation. Thin Solid Films 307, 200-202 (1997)

13. Valencia, H.Y., Moreno, L.C., Ardila, A.M.: Structural, electrical and optical analysis of ITO thin films prepared by sol-gel. Microelectron. J. 39, 1356-1357 (2008)
14. Jiao, Z., Wu, M., Gu, J., Sun, X.: The gas sensing characteristics of ITO thin film prepared by sol-gel method. Sens Actuators B Chem 94, 216-221 (2003)

15. Kundu, S., Biswas, P.K.: Synthesis and photoluminescence property of nanostructured sol-gel indium tin oxide film on glass. Chem. Phys. Lett. 414, 107-110 (2005)

16. Harrison, P., McGiveron, J., Harrison, C.: The effect of preparative conditions on the morphology of indium oxide and hydroxide. J. Sol-Gel. Sci. Technol. 2, 295-299 (1994)

17. Biswas, P.K., De, A., Dua, L.K., Chkoda, L.: Work function of sol-gel indium tin oxide (ITO) films on glass. Appl. Surf. Sci. 253, 1953-1959 (2006)

18. Sarhaddi, R., Shahtahmasebi, N., Rezaee Rokn-Abadi, M., Bagheri-Mohagheghi, M.M.: Effect of post-annealing temperature on nano-structure and energy band gap of indium tin oxide (ITO) nano-particles synthesized by polymerizing complexing sol-gel method. Phys. E 43, 452-457 (2010)

19. Djaoued, Y., Vu Hong, P., Badilescu, S., Ashrit, P.V., Girouard, F.E., Vo-Van, T.: sol-gel-prepared ITO films for electrochromic systems. Thin Solid Films 293, 108-112 (1997)

20. Legnani, C., Lima, S.A.M., Oliveira, H.H.S., Quirino, W.G., Machado, R., Santos, R.M.B., Davolos, M.R., Achete, C.A., Cremona, M.: Indium tin oxide films prepared via wet chemical route. Thin Solid Films 516, 193-197 (2007)

21. Aegerter, M.A., Al-Dahoudi, N.: Wet-chemical processing of transparent and antiglare conducting ITO coating on plastic substrates. J. Sol-Gel. Sci. Technol. 27, 81-89 (2003)

22. Han, C.-H., Han, S.-D., Gwak, J., Khatkar, S.P.: Synthesis of indium tin oxide (ITO) and fluorine-doped tin oxide (FTO) nanopowder by sol-gel combustion hybrid method. Mater. Lett. 61, 1701-1703 (2007)

23. Al-Dahoudi, N., Aegerter, M.A.: Comparative study of transparent conductive $\mathrm{In}_{2} \mathrm{O}_{3}: \mathrm{Sn}$ (ITO) coatings made using a sol and a nanoparticle suspension. Thin Solid Films 502, 193-197 (2006)

24. Ting, C-.C., Cheng, W.-L., Lin, G.-C.: Structural and opto-electrical properties of the tin-doped indium oxide thin films fabricated by the wet chemical method with different indium starting materials. Thin Solid Films 519, 4286-4292 (2011)

25. Benoy, M., Mohammed, E., Suresh Babu, M., Binu, P., Pradeep, B.: Thickness dependence of the properties of indium tin oxide (ITO) FILMS prepared by activated reactive evaporation. Braz. J. Phys. 39, 629-632 (2009)

26. Huang, C.J., Su, Y.K., Wu, S.L.: The effect of solvent on the etching of ITO electrode. Mater. Chem. Phys. 84, 146-150 (2004)

27. Artaki, I., Zerda, T., Jonas, J.: Solvent effects on the condensation stage of the sol-gel process. J. Non-Cryst. Solids 81, 381-395 (1986)

28. Fallah, H.R., Ghasemi, M., Hassanzadeh, A.: Influence of heat treatment on structural, electrical, impedance and optical properties of nanocrystalline ITO films grown on glass at room temperature prepared by electron beam evaporation. Phys. E 39, 69-74 (2007)

29. Li, Z.-H., Ke, Y.-P., Ren, D.-Y.: Effects of heat treatment on morphological, optical and electrical properties of ITO films by sol-gel technique. Trans. Nonferrous. Metals Soc. China 18, 366-371 (2008) 